\title{
Masyarakat Muslim Melayu di Singapura: Kajian Terhadap Isu dan Tantangan dalam Dakwah dan Pemikiran Islam Era Globalisasi
}

\author{
WZ Kamaruddin bin Wan $\mathrm{Ali}^{1}$
}

Ahmad Zuhdi bin Ismail ${ }^{2}$

\begin{abstract}
This paper aims to examine and assess the position of Islam as al-Din or religion for Malay Muslim community in Singapore. By using primary and secondary sources in the field of Islamic thought, the main and primary issues faced Malay Moslem society from various ranks, as well as internal, external and et cetera in addition to studying the methods and approaches applied by MUIS (Majelis Ugama Islam Singapore) specifically as the Islamic supreme and organization in the republic to solve the problems that arise in society since the first. The result of the study showed that Islam in Singapore is ASWJ (Ahlus Sunnah Wal Jamaah), as any other country in the overseas, but rather obvious distinction is due to the nature and attitude of openness and positiveness shown by Malay Muslim society in accepting diversity and different forms and thoughts. In summary, they are united in the difference "agree to disagree."
\end{abstract}

Keywords: Malay Muslims, Islamic thought

Abstrak: Makalah ini adalah bertujuan untuk meneliti dan mengkaji kedudukan Islam sebagai al-Din atau agama bagi masyarakat Muslim Melayu di Singapura. Dengan menggunakan sumber-sumber primer dan sekunder dalam bidang pemikiran Islam, isu-isu utama dan primer yang dihadapi masyarakat Muslim Melayu dari berbagai peringkat, juga tantangan baik internal, eksternal dan seumpamanya di samping untuk mengkaji metode dan pendekatan yang diaplikasi MUIS (Majelis Ugama Islam Singapura) secara khusus sebagai badan dan organisasi tertinggi berkaitan Islam di republik itu dalam penyelesaian masalah dan persoalan yang timbul dalam masyarakat dari masa ke masa. Hasil kajian memperlihatkan bahwa Islam di Singapura berwajah ASWJ (Ahlus Sunnah Wal Jamaah), sama seperti negara lain di rantau ini, tetapi perbedaan yang agak jelas adalah karena sifat dan sikap keterbukaan dan positif yang ditunjukkan masyarakat Muslim Melayu dalam menerima keberagaman dan perbedaan bentuk dan pemikiran yang berbeda. Ringkasnya, mereka sedia bersatu dalam perbedaan "agree untuk disagree."

Katakunci: Muslim Melayu, pemikiran Islam

Pendahuluan

Masyarakat Muslim di mana saja mereka berada pada hari ini sentiasa berhadapan berbagai isu dan tantangan dalam era globalisasi khususnya dalam bidang pemikiran Islam. Isu dan tantangan lebih merupakan ujian, mihnah dan ibtila yang disediakan Allah (s.w.t) untuk sama ada menambahkan kekuatan maupun menguji kekuatan sedia ada, yang pasti disediakan ganjarannya dalam berbagai bentuk. Kedinamikan dan kepasifan sesuatu masyarakat, bahasa, budaya, bangsa dan negara bergantung kepada kekuatan dan kelemahan mereka menghadapi isu dan tantangan internal maupun luaran.

${ }^{1}$ Profesor Madya pada Jabatan Akidah dan Pemikiran Islam, Akademi Pengajian Islam, Universiti Malaya, Kuala Lumpur Malaysia

${ }^{2}$ Dosen tetap pada Jabatan Akidah dan Pemikiran Islam, Akademi Pengajian Islam, Universiti Malaya, Kuala Lumpur Malaysia 
Muslim Melayu merupakan fokus artikel ini apatah lagi Melayu di Singapura merupakan golongan minoritas, dan mereka juga dari segi peratusan terbesarnya adalah Muslim dan menjadikan Islam sebagai sistem hidup mereka. Agak menarik untuk berbicara tentang Melayu karena mereka merupakan penghuni asal yang mayoritas di jugau Temasik dahulu, tetapi kini berubah menjadi golongan minoritas.

Bidang Pemikiran Islam di sini merujuk kepada bidang-bidang berkaitan akidah [Usuluddin], falsafah, tasawuf, teologi [Kalam] dan perbandingan agama yang berdasarkan sumber primer dalam Islam yaitu, Kalam Allah (s.w.t) al-Qur'an al-karim dan Hadith Nabi Muhammad (s.a.w) yang mengaplikasi metode-metode tertentu yang dibenarkan dalam Islam sebagai suatu sistem hidup atau "a way of life" dan kaedah pemikiran kaum muslimin.

Republik Singapura tidak terkecuali dilanda berbagai persoalan, isu dan tantangan yang datang dari dalam maupun luar. Bagaimanapun, isu dan tantangan yang dihadapi berbeda berbanding negara-negara lain di rantau ini seperti Malaysia, Brunei, Indonesia, Thailand, Filipina dan Vietnam. Kajian dan penyelidikan ini bertujuan untuk meneliti kedua-dua aspek, isu dan tantangan meliputi bidang-bidang yang telah dinyatakan terdahulu.

\section{Kedudukan Islam di Singapura}

Singapura seperti yang diketahui umum merupakan sebuah negara sekular yang tidak memberikan penekanan kepada agama dan bangsa sebagai terasnya, biarpun ia didominasi bangsa Cina selaku golongan mayoritas, apalagi mereka juga menganut Buddhisme sebagai agama dan kepercayaan. Dalam keadaan inilah, Islam dan Melayu terbabit sebagai sebagian dari kelompok yang membentuk identitas Singapura yang dikenal kini.

Diperlihatkan bahwa Islam sebagai al-Din [a way of life] bagi kaum muslimin yang merupakan golongan minoritas di Republik Singapura adalah diakui oleh kerajaan Singapura berdasarkan peruntukan dalam Perlembagaan Republik Singapura. Bagaimanapun, peruntukan tersebut dikemukakan dalam bentuk yang umum semata-mata. Tiada keterangan yang jelas mengenainya. Untuk mengetahui kedudukan Islam secara lebih mendalam, pendetailan mengenainya perlu dirujuk kepada badan atau majlis yang didirikan dengan tujuan yang spesifik, yaitu untuk mengendalikan semua urusan dan perkara berkaitan agama di republik tersebut.

Islam diberikan pengakuan sebagai salah sebuah agama di republik Singapura. Persoalan yang biasa ditanyakan adalah berhubung dengan aliran pemikiran yang diterimapakai dalam konteks Islam yang diamalkan itu. Di negara-negara lain di rantau ini seperti Malaysia, Brunei, Indonesia, Thailand, Philipina dan Vietnam, Islam versi Ahl al-Sunnah wa al-Jama'ah adalah begitu dominan dan berpengaruh besar serta diterima secara resmi. Apakah Singapura juga mengikuti Islam versi aliran pemikiran yang sama atau sebaliknya, sesuatu yang menarik untuk diperhatikan? Apakah juga signifikan dan dampaknya kepada masyarakat Muslim berbangsa Melayu di Singapura? Adakah mereka turut sama menerima nasib dan merasai pengalaman yang sama seperti yang lain-lain?

Dari segi kedudukan Islam, berdasarkan keterangan yang dikemukakan oleh Majlis Ugama Islam Singapura (MUIS) selaku pihak pemerintah tertinggi yang bertanggungjawab terhadap Islam dan masyarakat Muslim Melayu di negara ini, dikatakan bahwa Islam di 
Singapura adalah berwajah Ahl al-Sunnah wa al-Jama'ah [ASWJ] yang pada dasarnya telah diakui sebagai mazhab resmi bagi republik tersebut. Ini dapat dilihat dari kenyataan berikut berdasarkan Administration of Muslim Law Act [AMLA] yang menyebutkan:

"Article 152 of the Constitution of the Republic of Singapore guarantees the rights of minority communities to their religious belief and practice. This allows for Muslims to practice their Islamic faith in Singapore. The Administration of the Muslim Law Act enacted in 1966 outlines the sphere of Muslim activities in the public and legal domain." "Muslims in Singapore live their religious life according to the Ahlus Sunnah wal Jamaah. With regards to the legal school of thought, the Syafie school is followed by the majority of Muslims. Fatwas are also mainly issued according to this school, as mentioned in the Administration of Muslims Law Act (AMLA). ${ }^{3}$

Secara lebih jelas seperti dalam keterangan di atas, ASWJ yang dikuatkuasa dan diamalkan sepenuhnya di sini merujuk kepada mazhab (madhhab) akidah Abu al-Hasan alAsy'ari dan mazhab Fiqh Muhammad ibn Idris al-Syafi'i, sama seperti keadaannya di Malaysia. Semua aspek Islam yang difahami masyarakat Melayu Muslim di republik ini adalah berteraskan kepada kedua-dua mazhab akidah dan fiqh tersebut, sama ada dari aspek asas dan penyebab, sumber, metode, pemikiran, penyelesaian isu dan tantangan dan sebagainya. Dengan kata-kata lain, ia merupakan mazhab yang mendominasi pemikiran masyarakat Melayu Muslim Singapura dalam segala aspek kehidupan mereka, baik fizikal, mental maupun spiritual.

Keterangan oleh MUIS tidak berbeda dengan kenyataan yang diberikan oleh badan dan pihak berkuasa agama di negara masing-masing di rantau ini. Pertanyaan selanjutnya adalah bagaimanakah juga kedudukan mazhab-mazhab selain ASWJ di Singapura? Adakah mereka berhadapan dengan isu dan tantangan berikutan kelainan mereka berbanding dengan mazhab yang diterima umum dan sedia ada?

Islam versi Ahlus Sunnah Wal Jamaah (ASWJ) boleh dianggap sebagai mazhab resmi di Singapura seperti yang termaktub dalam keterangan MUIS sendiri. Bagaimanapun, seperti juga dengan negara-negara mayoritas muslim lain, yang menjadi ahli dan berada kepada pertubuhan OIC, terdapat berbagai mazhab lain juga ada dan bergerak seiringan dengan mazhab yang mendominasi Singapura itu sendiri. Apatah lagi dalam dunia tanpa batasan, dan dalam era globalisasi dengan semua penjuru dunia terpapar kepada berbagai anasir luaran.

Di antara yang dapat diketahui sepanjang kajian ini dilakukan memperlihatkan bahwa aliran pemikiran dan mazhab al-Salafiyyah al-Wahhabiyyah, merujuk kepada para pengikut aliran al-Salaf, al-Salaf al-Salih dan al-Salafiyyah, pada umumnya dianggap Muslim dan turut dikenal dan diakui sebagai para pengikut Ahlus Sunnah Wal Jamaah (ASWJ) juga. Ini bererti mereka merupakan sebagian dari ASWJ dan dengan demikian, mereka dapat hidup bebas, bergerak, berfikrah, beramal dan beriman tanpa adanya halangan dan hambatan. Walaupun dalam beberapa keadaan, perasaan "keberatan" kelihatan, namun ia masih dalam lingkungan

\footnotetext{
${ }^{3}$ Untuk informasi lebih lanjut mengenai AMLA, silahkan rujuk halaman website berikut: http://statutes.agc.gov.sg/.
} 
yang diterima dan dibolehkan. Justeru, tidak timbul sebarang isu dan tantangan berkaitan dengannya, dan pada umumnya berada dalam pengawasan.

Aliran pemikiran Syi'ah yang telah sekian lama ada di negara tersebut juga, pada umumnya turut dianggap Muslim dan lebih dikenal sebagai sub-sekte al-Ja'fariyyah, alZaidiyyah dan al-Isma'iliyyah [Dawudiyyah]. Mereka diberikan kebebasan untuk mempercayai, mendakwahkan dan mengamalkan ajaran dan amalan yang mereka ikuti dalam lingkungan mereka dengan lokasi mereka diketahui. Wawancara dengan MUIS menunjukkan bahwa mereka mendapat pengakuan secara resmi sebagai salah sebuah aliran pemikiran dan mazhab dalam Islam, dan oleh yang demikian, tidak kelihatan sebarang masalah, halangan ataupun kekangan untuk mereka hidup bebas berseiringan dengan para pengikut mazhab ASWJ yang merupakan golongan Muslim Melayu mayoritas dan mazhab-mazhab lain di republik tersebut.

Berlainan juga dengan kedudukan Qadiani, karena seperti ditegaskan oleh pihak MUIS dan pihak pemerintah di Singapura bahwa mereka dianggap sebagai Non-Muslim dan tidak termasuk dalam Islam, ${ }^{4}$ Walaupun perkataan dan perbuatan yang mereka tunjukkan kelihatan seperti kaum muslimin juga. Justeru, layanan dan penghormatan dari pihak kaum muslimin terhadap mereka adalah hampir sama seperti golongan bukan muslim yang lain. Walaupun dalam berbagai keadaan, golongan ini menghendaki mereka diberikan pengakuan sebagai sebagian dari kaum muslimin, namun usaha tersebut gagal dan dilarang. Kerajaan Republik Singapura sendiri yang mendapat nasehat dari MUIS dalam perkara-perkara melibatkan Islam dan Muslim, turut mengambil sikap dan tindakan seperti yang dinasehatkan. Dengan kata-kata lain, apa saja keputusan yang dibuat oleh MUIS sebagai badan pemerintah agama yang diakui kerajaan Singapura, menjadi keputusan kerajaan.

Kajian ini turut mengkaji dan meneliti metode dan metodologi yang digunakan oleh pihak pemerintah dan masyarakat muslim Melayu Singapura, khususnya dalam konteks mengeluarkan sesuatu fatwa dan keputusan berkaitan isu-isu keagamaan terutama yang melibatkan persoalan akidah, Seperti difahamkan bahwa Jawatankuasa syar'iyyah akan berpandukan dasar-dasar berikut mengikut keutamaan:

1. Al-Qur'an.

2. Hadith.

3. Ijma'.

4. Qiyas.

5. Ijtihad.

Dari segi otoritas dan pertanggungjawaban terhadap Islam dan Muslim, badan berkaitan Islam yang tertinggi di Singapura adalah MUIS [Majlis Ugama Islam Singapura] ${ }^{5}$ yang berada di bawah Kementerian Dalam Negara Singapura. Badan atau Majlis ini dianggap mewakili kerajaan dan akan mengikut keperluan dan kehendak kerajaan Singapura.

${ }^{4}$ Sumber informasi: Wawancara bersama-sama dengan Ustaz Maas, Pegawai Eksekutif (Sementara), MUIS, 10 Disember 2007 di MUIS, Singapura, Bradell Road, Toa Payoh.

${ }^{5}$ Boleh dirujuk dalam laman web MUIS. 
Dalam konteks yang lebih spesifik, keanggotaan badan atau institusi berkaitan Islam di Singapura diketuai oleh PERGAS [Persatuan Ulama dan Guru-Guru Agama Singapura] yang terlibat secara khusus dalam bidang pendidikan. Persatuan ini dilihat mempunyai kedudukan dan memainkan peranan yang sangat penting dan berpengaruh besar di Singapura. Dilihat dari segi keahliannya juga, ia melibatkan keahlian yang besar terdiri dari para ulama dan asatizah yang perlu mendapatkan pengakuan menurut Asatizah Recognition Scheme [Skim Pengakuan Asatizah]. Proses ini dilakukan oleh PERGAS, dengan dibantu menurut panel bebas yang dipilih untuk menentukan guru dan ustaz yang boleh diangkat untuk mengajar di masjid-masjid di Singapura. ${ }^{6}$

Badan atau institusi seterusnya yang turut memberikan sumbangan mereka yang besar dalam bidang pendidikan selain PERGAS adalah PERDAUS [Pesatuan Pelajar Agama Dewasa Singapura [PERDAUS]. Dengan keadaan kedua-dua badan ini, bidang pendidikan Islam untuk tujuan pengajaran dan pendidikan agama adalah terpilih dan terkawal. Jadi, aspek-aspek pencegahan dan pengawalan awal telah dijalankan oleh kedua-dua badan tersebut.

Dari segi pengawasan institusi-institusi formal [Islam] dan non-formal [Islam] di Singapura dalam aspek-aspek berkaitan Pengajian Islam [Formal] dan [non-formal], dikatakan berada dalam pemantauan pihak pemerintah. Di negara yang relatifnya kecil, jumlah masjid adalah berjumlah 69 buah, diikuti madrasah sebanyak 6 buah madrasah. Madrasah-madrasah tersebut adalah madrasah resmi di Singapura yang diakui kerajaan dan pihak MUIS, dengan silabus resmi, dan madrasah-madrasah itu adalah madrasah Aljunied, Arabiyyah, Almaarif, Wak Tanjung, dan lain-lain.

Dari segi isu berkaitan Islam juga, Singapura juga tidak terlepas dari berbagai isu dan permasalahan, baik langsung atau tidak langsung, besar maupun kecil. Secara mudahnya, isu, masalah dan persoalan yang timbul boleh dikategorikan kepada isu-isu bersifat primer dan utama dan isu-isu bersifat sekunder. Untuk melihat secara lebih fokus, di antara isu-isu bersifat primer adalah seperti tersenarai secara ringkas seperti berikut:

Pertama: Isu kemazhaban dan isu khilafiah masih boleh ditangani. Pihak berkuasa agama pada umumnya tidak mempunyai kuasa untuk mengambil tindakan. Sekiranya sesuatu tindakan wajar dan perlu diambil oleh pihak berkuasa agama, ia juga sebenarnya bukanlah atas asas dan dasar perbedaan mazhab, tetapi lebih kepada dasar "Ketenteraman umum" dan "Keselamatan Negara." Dengan kata-kata lain, alasan berkaitan keagamaan tidak boleh mensabitkan kesalahan. Kesalahan yang boleh diambil tindakan adalah sekiranya ia mengganggu ketenteraman umum dan mempunyai implikasi ke atas keselamatan negara.

Kedua, Isu aliran pemikiran al-Wahhabiyyah karena kelainan pemikiran dan pendekatan. Aliran ini diketahui menurut golongan asatizah yang menuntut dan belajar di Arab Saudi. Jumlah mereka tidaklah begitu ramai dan tidak juga pemikiran mereka mendominasi masyarakat Muslim Melayu. Secara mudahnya, aliran pemikiran ini adalah masih dalam pengawasan pihak berkuasa agama. Aliran ini digerakkan secara bebas oleh Persatuan

6 Wawancara dengan Mohd Jakfar bin Hj. Embek, Ketua, Da'wah, Latihan dan Perkembangan, Persatuan Ulama dan Guru-Guru Agama Islam (Singapura) @ PERGAS, Wisma Indah, Jalan Changi, Singapura pada 11 Disember 2007, jam 2 petang di Wisma Indah, Jalan Changi, Singapura. 
Muhammadiyah Singapura yang terletak di Jalan Selamat, Kembangan. Ia bergerak sendiri dan bukan mendapat pengaruh dari luar, terutama gerakan Muhammadiyah di Indonesia.

Ketiga: Isu aliran pemikiran Syi' ah yang ada sejak sekian lama tetapi jumlah yang kecil dan minoritas, boleh bergerak dengan bebas tetapi statik dan tidak dinamik dan agresif, masih boleh berinteraksi dan berkomunikasi dengan baik. Aliran ini seperti yang diwarwarkan, diwakili oleh Persatuan Himpunan Belia Islam [HBI] yang pada suatu waktu dahulu mempunyai hubungan dengan ABIM Malaysia. Syi'ah Ismailiyyah Dawudiyyah [Dawoodi Bohra@Khoja] $]^{7}$ mempunyai sebuah masjid dikenal “masjid Syi'ah" di Singapura terutama bagi masyarakat berbangsa India/Pakistan, dikenal lokasinya di kawasan City Hall. Keadaan mereka diterima baik seperti yang lain-lain, bahkan tiada pengawasan dan pemantauan rapi diberikan. Mereka juga tidak dilihat sebagai ancaman dan tidak juga sebagai pengancam. Dengan demikian, perhubungan adalah dalam bentuk yang harmoni dan saling hormat menghormati.

Keempat: Isu kelompok Qadiani seperti yang dijelaskan lebih awal adalah isu yang bukanlah komplikated. Mereka memang tidak diakui dan karena itu, dianggap bukan muslim [non-muslim]. Bagaimanapun, mereka diberikan kebebasan, tidak dikongkong dan bahkan turut mempunyai sebuah "masjid" mereka sendiri. Lokasi "masjid" mereka terletak di Geylang. Oleh karena mereka tidak mendapat pengakuan sebagai muslim oleh pihak MUIS dan kerajaan, maka semua yang berkaitan dengan mereka termasuk tempat ibadat tidak diakui sebagai "masjid".

Kelima: Isu "isme" @ Ism meliputi isu radikalisme dan terrorisme dikatakan dipelopori Jemaah Islamiah, seperti yang dilaporkan dalam kajian Muhamad Hanif Hasan [pengkaji Singapura dari Nanyang Technology University - S.Rajaratnam School of International Studies]. Isu ini timbul dikatakan berpenyebab dari peranan dan pengaruh guru-guru tidak bertauliah [tidak mendapat Skim Pengakuan MUIS].

Keenam: Isu Jemaah Islamiah [JI] dikatakan muncul di republik ini akibat dari peranan dan pengaruh internet. Mereka pernah mendapat tempat pada suatu tempoh masa tetapi mengikut maklumat terkini, Jemaah ini hampir tiada lagi, karena kebanyakan anggota yang terlibat telah ditangkap oleh pihak berkuasa Singapura.

Ketujuh: Isu liberalisme [liberalism] yang menyebabkan timbulnya persoalan "gay", hamba wanita [women slaves] yang menggugat golongan remaja Muslim secara khusus. Isu ini agak serius karena ia menimbulkan berbagai masalah remaja seperti luar nikah dan lain-lain. Isu "Intelegensia" juga dikatakan menjadi penyebab dan faktor kepada liberalisme dan women slaves.

Kedelapan: Isu khilafiah antara aliran Madinah [gabungan lulusan Madinah] menentang aliran al-Azhari [gabungan lulusan al-Azhar]. Kedua-duanya adalah dari aliran agama yang mendapat pendidikan formal dari dua institusi pendidikan tinggi luar negara yang berbeda, yang akhirnya menatijahkan perbedaan pandangan, pemikiran dan pendekatan. Walaupun secara realitinya, tiada apa-apa yang sepatutnya dibimbangkan namun isu sifat dan sikap yang keterlaluan dilihat menjadi penyebab masalah. Jadi, persoalan pokoknya bukanlah isu agama

${ }^{7}$ NADI [Pulse of the Singapore Muslim Community], Terbitan MUIS, July-September 2007, Vol.03/07, h.7. 
tetapi isu ketaksuban ['asabiyyah] melampau yang ada dalam kalangan mereka. Secara umumnya, ia masih di dalam pengawasan MUIS dan PERGAS dan isu-isu yang timbul kebanyakannya dalam bidang syariah. Ini karena guru-guru [asatizah] yang terlibat mendapat pengakuan MUIS dan juga mempunyai keahlian dalam PERGAS itu sendiri selaku badan atau persatuan yang mewakili mereka.

Kesembilan: Isu tarekat [tariqah] juga merupakan isu yang besar tetapi hanya di kalangan asatizah yang berpendidikan Islam pada peringkat tinggi saja, manakala di kalangan muslim umum, ia tidak terjadi. Terdapat beberapa tarekat di Singapura seperti Ahmadiyah dll, perbedaan tetap ada tidak dalam pengawasan MUIS. ${ }^{8}$

Kesepuluh: Isu ajaran sesat - telah ditangani dengan baik menurut kajian dan penyelidikan oleh Presiden PERDAUS, Hj. Embek Ali dibantu oleh MUIS menurut penerbitan buku Noktah Hitam, terbitan MUIS dengan kerjasama PERDAUS. Ajaran sesat yang ada adalah seperti Martabat Tujuh, Ilmu Bungkus dll, manakala ajaran sesat yang ada kini adalah dalam bentuk isme-isme baru seperti dikemukakan.

Kesebelas: Isu Faham Ingkar Sunnah [Anti-hadith] - pojugar suatu masa dahulu tetapi tidak masa ini.

Kedua belas: Isu pemikiran menurut ideologi diperoleh dari guru-guru agama, internet dengan pengaruh yang besar dan menggugat.

Ketiga belas: Isu berkaitan Pemikiran Islam - yaitu persoalan memperkukuhkan identitas Muslim. $^{9}$

Keempat belas: Isu yang timbul di kalangan muslim dengan non-muslim adalah tentang "racial harmony", terutamanya pengaruh dari 9/11 dan Jemaah Islamiah yang dianggap menggugat ketenteraman dan keselamatan umum, menyebabkan ketakutan kepada non-muslim. Usaha dilakukan di pihak MUIS dan badan-badan agama juga menurut National University of Singapore [NUS] untuk mendekatkan non-muslim kembali menurut "inter-religious dialogue", namun belum begitu berhasil. ${ }^{10}$

Isu berkaitan ajaran sesat hanya dianggap "personal domain" terutama melibatkan ajaran sesat. Isu-isu agama di Singapura lebih tertumpu kepada bidang syariah karena beberapa alasan:

Pertama: MUIS merupakan badan induk di bawah KDN Singapura, mengikut keperluan dan kehendak kerajaan Singapura. Oleh karena kerajaan lebih tertumpu kepada bidang ekonomi [transaksi], justeru MUIS juga mengarah kepada bidang syariah dalam pengisian asatizahnya.

Kedua: Kebanyakan guru menggalakkan pelajar [asatizah] mendalami bidang syariah yang dilihat lebih penting dalam konteks Singapura dan keperluannya.

Ketiga: Isu asatizah mengikut kawan dalam pemilihan kursus syariah ketika di universiti.

${ }^{8}$ Wawancara dengan Mokson bin Mahori, Wakil Ketua [Vice Principal] Madrasah Aljunied al-Islamiah [Aljunied Islamic School, Singapore] - Wawancara di kantornya, Madrasah Aljunied Islamiah, 30 Victoria Lane Singapore 198424 pada 12 Disember 2007 pada jam 2 petang.

${ }^{9}$ Wawancara bersama-sama Muhammad Ma'az bin Sallim, Eksekutif [Temporary], Pejabat Mufti, MUIS, Bradell Road, Singapura. Wawancara di MUIS, pada 10 Disember 2007 jam 12 tengahhari.

${ }^{10}$ Wawancara dengan Syed Nasir Syed Omar Alsagoff di Masjid AlKhair, Choa Chu Kang pada 13 Disember 2007 jam 11 pagi. 
Dari segi isu-isu sekunder juga, ia dilihat sebagai lanjutan dari isu-isu utama menyebabkan timbulnya isu "gay" dan "women slaves" oleh golongan penyokong Liberalisme, timbulnya isu Jemaah Islamiah [JI] dengan penyebab, faktor dan pengaruhnya, ${ }^{11}$ timbulnya isu "racial harmony" menyebabkan keperluan kepada inter-religious dialogue. Usaha pernah dilakukan oleh Ustaz Syed Nasir dengan kerjasama Dr. Farid al-Attas dari National University of Singapore [NUS]. Di kalangan muslim, isu keturunan "Habaib" [Habib], khususnya di kalangan kelompok Yamani / al-Hadrami, dianggap isu sekunder dan tidak begitu penting. Namun, masyarakat Muslim Melayu Singapura sering membincangkannya dalam kehidupan mereka seharian.

\section{Tantangan di Singapura Berkaitan Dakwah Akidah dan Pemikiran Islam:}

Dalam konteks tantangan, secara umumnya ia bolehlah dikategorikan kepada dua yaitu tantangan primer dan tantangan sekunder. Apa yang dimaksudkan dengan tantangan primer di sini merujuk kepada tantangan yang paling mendasar, utama dan fundamental kepada Islam dan kaum muslimin di Singapura manakala tantangan sekunder juga lebih kepada tantangan, persoalan dan permasalahan yang timbul dari tantangan dan persoalan utama dan fundamental tadi.

Dari segi tantangan fundamental ini, di antara yang terpenting adalah sebagai berikut:

Pertama, tantangan dalam usaha pengekalan dalam mempertahankan kedudukan Islam sebagai "a way of life" bagi golongan Muslim Melayu di Republik Singapura yang merupakan golongan minoritas.

Kedua, tantangan dalam usaha dan langkah untuk mengekalkan aliran pemikiran @ madhhab Ahl al-Sunnah wa al-Jama'ah sebagai aliran pemikiran resmi dan ikutan utama dalam semua aspek kehidupan, meliputi usuluddin dan syariah, berhadapan dengan era globalisasi dan dunia tanpa batasan dengan berbagai tantangan dari dalam dan luar. Dari dalam merujuk kepada golongan Muslim Melayu Singapura itu sendiri manakala dari luar juga merujuk kepada golongan-golongan muslim China, India, Arab dan lain-lain.

Ketiga, tantangan dalam usaha mengekalkan keotoritasan badan tertinggi berkaitan Islam di Singapura yang diketuai MUIS, karena dari segi otoritas, ia tidak mempunyai kuasa untuk membuat keputusan berkaitan Islam. Ia hanya memberikan nasehat dan pandangan kepada kerajaan republik tersebut dalam isu-isu berkaitan Islam.

Keempat, tantangan dalam usaha mempertahankan Islam hanya boleh dilakukan menurut perkara-perkara berkaitan "ketenteraman umum" dan "keselamatan dalam negeri" saja. Tindakan hanya akan diambil oleh kerajaan republik tersebut sekiranya ia berkaitan dengan perkara di atas. Isu-isu yang tidak berkaitan dianggap isu-isu biasa. Contoh: Isu Qadiani, walaupun tidak diakui MUIS, namun mereka bebas dan ada dalam kelompok tersendiri dan tanpa tindakan. Isu ini tidak mudah diselesaikan karena otoritas atau kuasa yang terbatas.

Kelima, tantangan dalam usaha untuk mengukuhkan Islam menurut pengukuhan akidah dan pemikiran Islam menjadi suatu bebanan karena generasi pelapis lebih menjuruskan

${ }^{11}$ Wawancara dengan Ustaz Syed Nasir Syed Omar alSagoff, Masjid al-Khair, Choa Chu Kang pada 13 Disember 2007. 
pemikiran mereka kepada bidang syariah semata-mata karena permintaan masyarakat Muslim Melayu Singapura.

Tantangan sekunder yang ditimbulkan lanjutan dan ekoran dari tantangan, persoalan dan permasalahan fundamental juga adalah seperti berikut, di antaranya:

Pertama, isu perbedaan aliran pemikiran di Singapura, tidaklah seperti yang terjadi di Malaysia. Keberagaman diterima dengan baik. Justeru, keadaan aliran Wahhabi, Syi'ah dan lain-lain dapat diterima sebagaimana seadanya. Apa yang semua pihak secara umum bersepakat dan bersependapat adalah untuk tidak bersikap ekstrim atau taksub terhadap sesuatu puak, pihak, kumjugan sehingga melihat segala-galanya adalah mereka saja.

Kedua, isu berkaitan Islam lebih banyak menjurus kepada bidang syariah, berbanding Usuluddin dan akidah. Fenomena ini sekiranya tidak ditangani secara bijaksana oleh pihak pemerintah pada jangkamasa panjang mungkin akan menimbulkan masalah dan problem baru yang lebih berakarumbi kepada persoalan kepercayaan dan keyakinan terhadap agama secara umumnya, dan Islam secara khusus.

Ketiga, isu kemasyarakatan atau "social problems" yang ada adalah kecil walaupun dampaknya besar kepada masyarakat Muslim Melayu di Singapura. Contoh: isu "gay", "women slaves", Jemaah Islamiah, "racial harmony" dan lain-lain.

\section{Analisis dan Dapatan Kajian di Singapura:}

Pertama: Perkara yang menarik perhatian ditemui dalam kajian adalah tentang kedudukan Islam di Singapura dan perbandingannya di Malaysia. Di Malaysia, Islam termaktub dalam perlembagaan, sedangkan di Singapura sebaliknya, dianggap sama dengan agama-agama lain, dengan setiap agama bebas diamalkan oleh para penganutnya masing-masing.

Kedua: Di Malaysia, Islam bercorak Ahl al-Sunnah wa al-Jama'ah saja boleh diamalkan. Lain-lain tidak dibenarkan. Di Singapura, kebebasan ada di kalangan madhhab dalam Islam untuk bebas mengamalkan aliran atau madhhab masing-masing. Semua mendapat hak yang sama tanpa halangan, dan perasaan berlapang dada dan berfikiran terbuka ada.

Ketiga: Bidang dalam Islam paling dominan di Singapura adalah syariah, dengan hampir kebanyakan tokoh agama mempunyai kelulusan dalam bidang syariah, dan amat sedikit berkelulusan bidang Usuluddin. Justeru, permasalahan dalam bidang Pemikiran Islam sukar ditangani secara ilmiah atau akademik karena keterbatasan tokoh cendekiawan dalam bidang tersebut. Kelihatan, bidang ini akan terus dikuasai karena permintaan Melayu Muslim Singapura lebih banyak dalam bidang ini.

Keempat: Isu utama di Singapura bukanlah isu akidah dan pemikiran Islam, seperti ajaran sesat, madhhab, sebaliknya isu-isu itu boleh dianggap sederhana dan kecil saja seperti perbedaan hukum dan sebagainya.

Kelima: Tantangan di Singapura boleh dikatakan hampir tiada, karena telah banyak diatasi seperti ajaran sesat yang telah tiada, manakala terrorisme adalah dari pengaruh luar yang juga telah ditumpaskan. Tantangan yang sedia ada adalah bersifat setempat dan internal Singapura saja. 
Keenam: Dengan situasi dan kondisi yang ada di Singapura, dengan isu utama bukan berkaitan Pemikiran Islam, manakala tantangan besar hampir tiada, keadaan ini menyebabkan metode berfikir dan perkembangan pemikiran terutama pemikiran Islam di Singapura agak berbeda dengan Malaysia.

Ketujuh: Persoalan metodologi yang diaplikasi MUIS secara khusus sebagai badan dan organisasi tertinggi berkaitan Islam di Singapura dalam penyelesaian masalah dan persoalan yang timbul dalam masyarakat muslim dari masa ke masa dapat dilihat adalah berdasarkan kepada Islam beraliran ASWJ dengan rujukan khusus kepada al-Asya'irah dan al-Syafi'iyyah seperti di Malaysia juga.

\section{Simpulan}

Islam merupakan al-Din atau cara dan sistem hidup bagi semua manusia yang mahu mengikutinya dan mengakuinya sebagai "sistem hidup dari Allah, kepada Allah dan untuk Allah." Singapura merupakan sebuah negara Muslim Melayu atau negara beragama Islam dan bermayoritas Melayu suatu masa dahulu. Kedatangan British telah mengubahkan senario secara drastik sehingga akhirnya ia berada dalam keadaan sebaliknya seperti hari ini. Dalam negara berdasarkan sistem sekular, Islam tidak disebut dan tiada dalam peruntukan Perlembagaan Singapura sebagai salah sebuah agama, apatah lagi agama bagi negara. Walaupun begitu, kerajaan republik Singapura memberikan penghormatan kepada Islam dengan menyerahkan segala urusannya di bawah kendalian Majlis Ugama Islam Singapura (MUIS) yang bertindak sebagai badan penasehat kerajaan, dengan segala nasehatnya dalam hal ehwal agama diberikan perhatian dan pertimbangan. Menurut Administration of Muslim Law Act (AMLA), Islam diberikan tempat berdasarkan artikel 152, Perlembagaan Singapura dan seterusnya, mazhab Ahl al-Sunnah wa al-Jama'ah (ASWJ) diakui sebagai mazhab terbesar. Ia dijadikan pengukur dan asas pemikiran Islam di Singapura. Namun, ruang untuk mazhab-mazhab selainnya bebas diamalkan adalah terbuka luas selama mereka berada dalam Islam. Justeru, kajian memperlihatkan keterbukaan terjadi selama ia tidak dilihat menjadi ancaman dalam dua isu besar, ketenteraman umum dan keselamatan negara. Berdasarkan senario dan situasi ini, isu dan persoalan yang muncul berkaitan Muslim Melayu adalah dalam lingkungan tersebut. Disebabkan kedudukan Islam yang terbatas, Islam dan Muslim Melayu berhadapan dengan berbagai isu dan tantangan, dalam survivalnya terhadap ancaman dalam dan luar. Isu dan persoalan utama di Singapura dalam bidang pemikiran, usuluddin atau akidah tidak begitu berbeda dengan negara-negara serantau. Isu yang timbul kebanyakan berkaitan dengan sesuatu yang datang dari luar Singapura, menurut pendidikan, pendedahan, media massa dan akhirnya memberikan pengaruh dan impak kepada pemikiran Muslim Melayu Singapura. Sesuatu yang menarik perhatian adalah kebanyakan isu berkisar dalam bidang syariah karena tuntutan masyarakat kelihatan lebih dominan dalam bidang ini. Pengaruhnya, kebanyakan lulusan agama Singapura datang dari bidang ini dan amat sedikit lulusan dalam bidang usuluddin dan akidah dihasilkan. Kelemahan akibat kekurangan pemikir dalam bidang usuluddin akan pasti memberikan impak negatif pada jangka panjang memandangkan dunia global tanpa batasan akan menghadapkan tantangan pemikiran yang lebih besar dan lebih berat. Seperkara yang menarik juga, Muslim Melayu lebih terbuka dari segi pemikiran, tidak taksub. 


\section{Daftar Pustaka}

Noktah Hitam: Ajaran Sesat di Singapura, Terbitan MUIS dengan kerjasama PERDAUS, Cet. Mediaprint (antara tahun-tahun 1997 @ 98) [tiada dalam penerbitan]

Kesederhanaan Dalam Islam: dalam konteks Masyarakat Islam Singapura, PERGAS, Cet.I, 2004. [Laman web: www.pergas.org.sg] @ [English version - Moderation in Islam: in the Context of Muslim Community in Singapore, First Edition, 2004]

Abdul Rahman Mohamad, Aku Bukan Wahhabi, Fiqh Consultancy and Services, Singapore, cet.I, Januari 2004.

In Quest of Excellence: A Story of Singapore Malays, Yayasan Mendaki Singapura, Oktober 2002.

Muhammad Hanif Hassan, Unlicensed to kill: Countering Imam Samudra's Justification for the Bali Bombing, [meneruskan pengajian di peringkat $\mathrm{PhD}$ dan berkhidmat di Nanyang Technology University - S.Rajaratnam School of International Studies bersama-sama penganalisis, Mahfuh $\mathrm{Hj}$ Halimi]

Hj Osman bin Jantan, Pedoman Ilmu Tauhid, Pustaka Nasional Pte Ltd, Singapura, Cet. XIV, 2005.

Ustaz Jaafar Omar Banafie, Asas Akidah Islam, Kerjaya Printing Industries Pre. Ltd, Singapore, Cet.I, 2006/1427.

Muhammad bin Muhammad Ishak, Kitab Tawhid (Inggeris), untuk bacaan umum dalam bidang akidah.

Dalam proses penulisan, buku tentang Ulama di Singapura, terbitan MUIS dengan kerjasama PERGAS.

\section{Daftar Wawancara}

Muhammad Irwan Hadi, Pegawai Eksekutif, Pejabat Mufti, Majlis Ugama Islam Singapura [MUIS], Toa Payoh, Singapura.

Mohd Jakfar bin Embek, Ketua, Da'wah, Latihan dan Perkembangan, Persatuan Ulama dan Guru-Guru Agama Islam (Singapura) @ PERGAS, Wisma Indah, Jalan Changi, Singapura. Wawancara pada 11 Disember 2007 di Wisma Indah, Jalan Changi, Singapura.

Muhammad Saiful Alam Shah bin Sudiman, Eksekutif Dakwah / Naib Kadi, Lembaga Pentadbir Masjid Kassim, Kembangan, Singapura.

Syed Nasir Syed Omar alSagoff, Pengarah Eksekutif, Masjid AlKhair, Choa Chu Kang, Singapura.

Hj Embek Ali, bekas Presiden PERDAUS [Persatuan Pelajar Agama Dewasa Singapura] dan penulis buku Noktah Hitam [tentang ajaran sesat di Singapura], terbitan MUIS dengan kerjasama PERDAUS.

Hasbi Hassan, Guru besar, Madrasah Aljunied al-Islamiah [Aljunied Islamic School, Singapore] yang juga Presiden PERGAS.

Mokson bin Mahori, Timbalan Pengetua [Vice Principal] Madrasah Aljunied al-Islamiah [Aljunied Islamic School, Singapore] - Wawancara di pejabatnya, Madrasah Aljunied 
Islamiah, 30 Victoria Lane Singapore 198424 pada 12 Disember 2007. [Rujuk: Laman web aljunied.edu.sg]

Muhammad Ma'az bin Sallim, Eksekutif [Temporary], Pejabat Mufti, MUIS, Toa Payoh, Singapura. Wawancara di MUIS, pada 10 Disember 2007.

Siti Khadijah Asghar, responden berjawatan guru Montessori dari Bedok North, Singapura.

Sulaiman, Wardah Books, Bussorah Street, Singapore.

Nordin, MuslimMedia, Kandahar Street, Singapore.

Abdul Kadir bin Abdul Malik, Pustaka Nasional, 448, Changi Road, Wisma Indah, Singapore 419975.

Rashidah G, pensyarah sambilan di Singapura, dan calon Ijazah Tinggi [MA] di sebuah universiti di Australia.

Suhaila, Syeikha dan Norhanisah, pelajar BA di APIUM, berasal dari Singapura. 